\title{
Romaanist ja rahvusest postkolonialismi diskursuses ${ }^{1}$
}

Patrick Parrinder "Nation \& Novel: The English Novel from its Origins to the Present Day" (Oxford, 2006. 502 Ik.); Peter Hitchcock „The Long Space: Transnationalism and Postcolonial Form" (Stanford, 2010. 295 Ik.); Natalie Melas "All the Difference in the World: Postcoloniality and the Ends of Comparison" (Stanford, 2007. 278 Ik.)

\section{Tiina Kirss}

Patrick Parrinderi inglise romaani ajalugu „Nation and Novel” („Rahvus ja romaan”, 2006) ning Peter Hitchcocki ja Natalie Melase kaasaegseid käsitlusi võrdlevast kirjandusteadusest "The Long Space” („Pikk ruum”, 2010) ja „All the Difference in the World”2 (2007) ajendas lugema ühe õpetamisülesande paine: vajadus „kultuuriliselt tõlkida” postkolonialismi mõistestikku oma loengutesse eesti romaanist. Postkolonialismi relevantsusest ja selle võimalustest on viimase viie aasta jooksul eesti kultuuri uurimises algatatud mitmeid dialooge, mille jätkamist kindlasti tõhustaks mõnede tuumakamate tekstide eestindamine. Võiks isegi väita, et ilma sellise tõlkevaevata ei saagi need dialoogid eesti kultuuriruumis kaugemale jõuda nende asemel jätkub pinnavirvenduslik terminoloogia ringlus ja kõige käibivus. Mõttelised struktuurid ning postkolonialistliku teooria jaoks eriti oluline pingeliste vaidluste taust vajavad süvavahendamist, seega siis teadlikku kultuuritõlget.

Kui postkolonialismi uurijate hulgas on figureerinud implitsiitne „triumviraat” Edward Said, Gayatri Chakravorty Spivak ja Homi K. Bhabha, siis viimase artiklikogumikud "Nation and Narration" (Bhabha 1990) ja "The Location of Culture" (Bhabha 1994) on jätnud teatud õõnsa tunde, eriti ehk rahvuse ja narratiivi seoste loomise suhtes. Bhabha kavaldavas, tabamatus ja hermeetilises kirjutamisviisis on rahvuse ja pika jutustuse suhe jäänud ühedimensiooniliseks, keskendudes vaid poliitilisele allegooriale. Aijaz Ahmed, kritiseerides Fredric Jamesoni, on osutanud poliitilise allegooria mõiste kasutamise reduktiivsusele, mille järgi ainus struktuur, mis põhistab „kolmanda maailma” vabariikides kirjutavate pikema proosa autorite teoseid, on „natsiooni allegooria” (Aijaz 2008: 101). Seevastu konkreetsem ja selgem on Benedict Andersoni sõnastatud mudel rahvusest kui ettekujutuslikust kogukonnast (ingl k imagined community), mille üheks ilminguks ja vahendiks on olnud romaan. Andersoni sõnastuses toimib rahvuse ja romaani suhe teatud ajaloolistes olukordades, eriti rahvuse

1 Artikkel on valminud ETF-i grandi nr 8530 toel.

2 Natalie Melase raamatu pealkirja tõlkimine eesti keelde on võimatu. Pealkiri tuleneb tavakeelsest kõnekäänust. Kui üks kõneleja ütleb teisele „But that makes all the difference in the world”, siis eesti keeles võiks sellises olukorras öelda „see ongi kaalukeel!” või „see muudab olukorra täiesti”. Melas võtab seda kõnekäändu teises tähenduses: maailmas - Edward Saidi mõttes konkreetselt „ilmastunud” maailmas, millele pole joonistatud mitte ainult esimene, vaid ka teine ja „kolmas” maailm - on erinevust nii palju, et erinevuse maksimalistlikkus ongi võrdlevas kirjanduses ja kultuuriteaduses kõige olulisemaks teguriks, kaalukeeleks. 
rajamise tingimustes. Kuigi Andersoni arutelu romaani ümber moodustab vaid väikese osa tema kuulsast raamatust „Imagined Communities” (vt Anderson 2006) ${ }^{3}$ ning tema põhilised näited tulenevad tema enda välitööpaigast Indoneesiast, Ladina-Ameerikast ja mitte Euroopa suurtest kirjandustraditsioonidest, siis kirjandusteaduses on see rahvuse/romaani kooslus üle võetud ahistooriliselt, kasutades seda igas võimalikus ülekandes, hoolimata ka tema näidete seostamise loogikast. Jonathan Culler osutab kurioossusele, et vaatamata sagedusele, millega Andersoni romaanikäsitlust tsiteeritakse, ei ole selle üle, mida ta romaani võimaluste kohta väidab, eriti diskuteeritud (Culler 2003: 32). Peter Hitchcocki sõnastuses: Andersonist on paarikümne lehekülje põhjal tehtud kirjanduskriitik ning tema "natsioonide grammatikast on vabalt konstrueeritud kirjanduslikke homoloogiaid" (Hitchcock 2010: 7).

Anderson käsitleb võrdlevalt ning analüütiliselt nelja pikemat erinevatest kultuuridest pärit proosafiktsiooni. ${ }^{4}$ Normatiivseks on aga kujunenud lihtsustatud vormel, et romaani dominandiks on rahvuse loomine ning et rahvuseloome üks peamistest tööriistadest on romaan kui kirjanduslik vorm. Sellise hüpoteesi tuletamine Andersoni raamatu teisest peatükist ei jäta kahe silma vahele mitte ainult valitud romaanide võrdleva analüüsi spetsiifika, vaid väite romaani ja ajalehe kultuurilooliste seoste kohta. Ajaleht ja romaan kui trükikapitalismi kaks „tehnilist võimalust” moodustasid lugejaskondi, kes suutsid end kujutleda virtuaalsete tervikutena. Simultaanne argilugemine, mida pakkus ajaleht, sisaldas omakorda pikki järjejutte, mis olid vormilt romaanid (Anderson 2006: 30). Ajaleheveergudel järjejutuna ilmunud romaanid ei ole ainus seos romaani ja ajalehe vahel, kuid nende seoste mõistmine sisaldab tõhusat väljakutset lugemise ajaloo uurijatele. Romaani ja ajalehe lugejaskondi ei saa sugugi mööndusteta samastada, isegi Andersoni modernse aja käsitluse avara vihmavarju all. ${ }^{5}$ Ka romaani uurijad, keda Andersoni modernse aja käsitlus ahvatleb, ei tohiks ajalehte romaanist lahti muukida, vaid mõelda nende omavahelised seosed lõpuni.

Patrick Parrinderi monograafia "Nation and Novel" lähtub küsimusest, mis teeb inglise romaani inglaslikkuse (ingl k Englishness) kandjaks? Kas on tähenduslikke seoseid romaani kui kirjandusliku žanri ja inglaslikkuse defineerimise vahel? Monograafia esimeses kahes peatükis võtab Parrinder arutlusele nii Andersoni seletuse romaani ja rahvuse

3 Raamatust on ilmunud kaks väljaannet, 1983. ja 1991. aastal. Teise väljaandesse, mille uustrükk ilmus 2006. aastal, on lisatud kaks uut peatükki ja uus sissejuhatus.

4 Need on Filipiini rahvuslase José Rizali 1887. aastal avaldatud romaan „Noli Me Tangere” („Ära puutu mind”), Francisco Baltazari 1861. aastal trükist ilmunud romaan „Pinagdaanang Buhay ni Florante at ni Laura sa Cahariang Albania” („Florante ja Laura lugu Albaaniast”), José Joaquin Fernandez de Lizardi 1816. aastal avaldatud romaan „El Periquillo Sarniento” ja indoneeslase Mas Marco Kartodikromo 1924. aastal järjejutuna avaldatud romaan „Semarang Hitam” („Must Semarang”, vt Anderson 2006: 32-37).

5 Anderson laenab Walter Benjaminilt mõiste homogeenne tühi aeg (ingl k homogeneous empty time), mis kehtib tema jaoks Euroopas alates 18. sajandist. 
seostest kui ka „kolooniatest pärit” ingliskeelse kirjanduse lõimumise emamaa kaanonisse, mis inglaslikkuse mõistet on mitmeti raputanud ja pööranud. Inglise romaanitraditsiooni jaoks olulise ingliskeelse postkoloniaalse kirjanduse kaasab Parrinder Edward Saidi afiliatsiooni mõiste abil: need, kes pole inglasteks sündinud, saavad inglasteks teadlike valikute kaudu, kuigi filiatsiooni ja afiliatsiooni suhe on dünaamiline, mõnikord vägagi labiilne. Andersoni põhiväitega - et ilukirjanduses kujutatud kogukonnad on ettekujutatud (imaginaarsed) kogukonnad - on Parrinder nõus, kuid ta ei rahuldu Franco Moretti sõnastusega, et "romaan on rahvusriigi sümboolne vorm" (Parrinder 2006: 14). Ta hoiatab, et nende kahe idee sidumine epigrammina võib viia ekslikele järeldustele. ${ }^{6}$ Jonathan Culler sõnastab Andersoni väite mittemõistmisest tekkinud eksitust täpsemalt. Andersoni jaoks pakub romaani struktuur soodsaid vormilisi võimalusi rahvuse kujutamiseks (ingl k structural conditions of possibility): kriitikud, keda huvitavad spetsiifiliste romaanide süžeed, teemad ja kujuteldavad maailmad, üritavad aga näidata, kuidas nende romaanide sisu toetab rahvuse kujundamist, õigustamist ja legitimeerimist. ${ }^{7}$ Kuigi Andersoni enda käsitluses esineb nii mõnigi kord libisemist ühelt väitelt teisele, tuleks Culleri arvates neid rangemalt eristada, kuna need osutavad erinevas suunas.

Kui Parrinderi raamatu ülesehitus võib jätta mulje, et tegemist on traditsioonilise, konservatiivse, kronoloogilise ülevaateteosega, siis ei ole see vale: oma eessõnas teatab Parrinder selgelt, et ta kirjutab kirjanduslugu. ${ }^{8}$ Samas aga defineerib autor inglise rahvuslikku identiteeti kompleksselt, hinnates kriitiliselt selliseid tegureid ja võimalikke lähtealuseid nagu rahvuslik iseloom, keelepõhisus, seos maaga. Korrigeerides neid kirjandusteadlasi, kes Andersoni lugedes on segamini ajanud rahvusriigi ja rahvuse mõiste, väidab Parrinder, et romaani seos rahvusega on mõeldav ainult siis, kui defineerime rahvust kui kultuurrahvust (sks k Kulturnation; vt Parrinder 2006: 17). See, mida lugeja saab teada Inglismaast, inglastest ja „inglise identiteedi” mitmuslikkusest romaanide kaudu, mida teistes kirjanduse liikides leidub ehk vähem, on ülekantud tähenduses lokaalne teadmine (ingl k local knowledge). Parrinderi mõtteline ülekanne antropoloog Clifford Geertzilt on teoreetiliselt

6 Ingl k „To put the two ideas together is as epigrammatic as it is ultimately mystifying".

7 „The power of Anderson's thesis about the novel is that it makes a formal condition of imagining the nation a structural condition of possibility. Critics who are interested in the plots, themes, and imaginative worlds of particular novels, have tended to transform that thesis into a claim about the way some novels, by their contents, help to encourage, shape, justify, or legitimate the nation - a different claim, though one of considerable interest. The fact that Anderson's own examples involve some slippage from one claim to the other helps to explain the critical reception but does not excuse it. Literary critics in particular ought to be skilled at distinguishing an argument about the implications and consequences of a literary form from claims about particular sorts of plots and thematic representations." (Culler 2003: 48.)

8 "Nation and Novel is a literary history of the English novel and its distinctive, often subversive contribution to ideas of nationhood" (Parrinder 2006: vii). 
ja lugemispragmaatiliselt värskendav ja ülimalt viljakas, pakkudes väljapääsu nii üldistamisIõksudest kui ka Bhabha kirjutiste võluvalt ambivalentsest (tema jüngritel kahjuks tihti aga deduktiivsest) allegoorilisusest. On huvitav, et vihjet Geertzile ei konkretiseeri Parrinder akadeemilise viitega. Viitamispalavikulises teaduskliimas mõjub värskendavana intertekstide välja- ning läbipaistvus just vihjelisusena. Kogu ingliskeelset proosat, inglise kirjandusvälja ja kultuuriruumi valdava sünteesijana väldib ta ahel- ja kobarviiteid, kasutades nende asemel joonealuseid seletusi, millest peaaegu igaüks sisaldab alusbibliograafiat ühe või teise probleemi mõistmiseks. Niisiis võtab Parrinder oma eessõnas kokku selle teadmise, mida romaan kui vorm lugejale annab: „Suur osa teadmisest, mida me romaane lugedes omandame, on omakandi tarkus; käsitleda romaane puhtal kujul imaginaarse maailmakunsti muuseumina võib meie kogemust pigem vaesestada kui rikastada"9 (Parrinder 2006: 2). Romaani ja etnograafia mõtteline lähedus on romaani lisaväärtus, mitte allahindlus esteetiliste funktsioonide arvelt. Pikk proosafiktsioon kõneleb tõepoolest rahvusest, kuigi mitte ainult sellest, ning ammugi ei saa see olla mahaloetava poliitilise agenda illustratsiooniks. Parrinderi inglise romaaniloo sissejuhatusest jätkus mõtlemisainet mitmeks loenguks, kuna Parrinderi põhiküsimus ning hüpotees romaani ja lokaalsuse kohta kehtib ka eesti romaani kohta, mille kogumaht on väiksem, mille "kohalikkust” on kord üle-, kord alahinnatud ning mille ajalugu on suurest Euroopa romaanitraditsioonidest lühem.

Rahulolematused postkolonialistlike romaanikäsitlustega, olgu siis rahvuse või rahvusriigi allegooriatega, või eeldus, et postkolonialistlik kirjutus on tingimata rahvuslik vastudiskursuse või koloniseerimiseelse kuldse aja nostalgiline fantaasia, kannustasid lugema Peter Hitchcocki monograafiat "The Long Space". Selle ahvatlev alapealkiri tõotas vastata kummitavale küsimusele, kas postkoloniaalset žanrispetsiifikat (mida Hitchcock ühes oma varasemas artiklis on nimetanud the genre of postcoloniality) on olemas ning kas on võimalik seda kohelda rahvusüleselt. Monograafia alguses püstitab autor põhiküsimuse, kuidas saab postkoloniaalsest kirjutusest mõelda viimasel ajal ümbermõtestatud maailmakirjanduse mõiste taustal. Nagu Benedict Anderson, alustab ka Hitchcock Indoneesia kirjandusega, täpsemalt Pramoedya Ananta Toeri ajalooliste romaanide tsükliga ${ }^{10}$, ning nagu Andersonil, on ka Hitchcockil vastavad keelelised pädevused: ta on suuteline Toeri tekste lugema ja analüüsima originaalkeeles. Hitchcocki tuletatud teoreetiline kontseptsioon „pikk ruum" (ingl k long space) on kohandatud kronotoopilisus, aegruum, milles ruumiline avarus ja ajaline kestvus moodustavad mõtteliselt rikka oksüümoroni. Kohaldatud mõistetega kaasnevad kultuuritõlke probleemid ning kohaldamise jätkukohad sageli ei reeda kohaldamise

9 „Much of the knowledge we acquire in reading novels is local knowledge and that considering them solely as an imaginary museum of world art can impoverish as well as enrich our experience."

10 The Buru Quartet. Penguin, 1990. 
piire ega sobivust. Vaatamata Hitchcocki mõttearendustele ning optimistlikele väidetele ei õnnestu tal pika ruumi mõiste kaudu maailmakirjanduse ja postkoloniaalse transnatsionalismi mõisteid ühildada. Järele jäävad muljetavaldavad lähilugemised ning teoreetiline brikolaaž.

Natalie Melase raamatu "All the Difference in the World” vorrdleva kirjandusteaduse metodoloogiline kriitika ei lähtu ainult hiljutistest distsipliinisisestest vaidlustest ja vaidlustest multikulturalismi ja eurotsentrismi üle nagu Gayatri Chakravorty Spivaki provokatiivne „The Death of a Discipline” (vt Spivak 2003) ja Modern Language Associationi juhatuse sponsoreeritud avalikud väitlused. Kahtlemata on need teosed ja vaidlused muutnud postkolonialismi ebamugavust tekitavad teoreetilised küsimused möödapääsmatuks. Melas esitab vaid põhiküsimuse komparativismi problemaatikast üldisemalt: mida me teeme, kui me „võrdleme” kirjandusteoseid või suuremaid üksusi, näiteks žanre, traditsioone, kirjanduslugusid? Hitchcocki ja Melase ühine territoorium ja vaidluspaik on mure komparativismi kummitavate metodoloogiliste kammitsate ning varjatud poliitiliste eelduste pärast. Melase probleemipüstitus algab aga mõistest mittemõõdetavus (ingl k incommensurability) ehk sellest, mida ei ole võimalik eri kirjanduste puhul võrrelda, ei kontrastiivselt ega inklusiivselt, isegi siis, kui tasalülitada stardipositsiooni erinevused postkoloniaalse kirjutuse ja emamaa kanoniseeritud kaalukuse vahel, „väikese” ja „suure” kirjanduse vahel. Melase strateegiat mittemõõdetavuse piire kaardistada on seostatud Edward Saidi niinimetatud kontrapunktse lugemisega, kus lähilugemises lubatakse ühel tekstil teist läbi valgustada ning seatakse tekstid üksteisega kõnelema. Melase raamatu peatükid on tihedad kontrapunktsed lähilugemised, igaüks nii terviklik, et analüüsi sillerdavus peidab lahtiseid otsi ning sedasama mittevõrreldavuse astet, mida ta rõhutada soovib. Valikud, milliseid raamatuid kontrapunktselt lugeda, võib ju teha nii sobivuse (näiteks intertekstuaalse vihjelisuse või ühe romaani süžee ümberpööramise või ümberkirjutamise abil teises) kui ka mittesobivuse alusel. Divergentsuse alusel tehtud romaanipaare Melase valikutes ei ole.

Hitchcock ja Melas püüavad erinevaid radu pidi arendada kirjandusuurimise võrdlevat meetodit ja pürgida transnatsionaalsele kirjanduskäsitlusele. Hitchcocki teoreetiliste mõistete ehitustöö tulemusena konstrueeritud uus mõiste eksotoopia võimaldab tuua pikad (mitmeköitelised) postkoloniaalsed romaanid rahvusvahelisele „mänguplatsile”, muuta need üleilmse virtuaalse rahvusvahelise kirjandusruumi osaks. Olulist võitu see lähteplatvorm teoste kontekstuaalsele lähilugemisele ei anna. Melase kontrapunktsed lugemised pakuvad komparativismi proovile panemiseks paremaid võimalusi ning ei sõltu kontseptuaalse sõnavara kombinatoorikast, vaid analüütiliste tööriistade intensiivsusest provokatiivsete lähilugemiste loomisel. Kuigi nii Hitchcock kui ka Melas ei pretendeeri sellele, et kirjutada kirjanduslugu, sidusat ega ka mitte katkestavat narratiivi ei rahvuspõhise ega globaalse kirjanduse kohta, siis tasuks nende kõrvale paigutada Parrinderi monograafia „Nation and Novel” sissejuhata- 
vad peatükid. Hitchcocki vallatu kontseptualiseerimine, Melase säravad lähilugemised ja mittemõõdetavuse mõiste ning Parrinderi kriitiliselt kahesuunaline liiklus rahvuse ning romaani ideede ja vormide vahel pakuvad häid teeviitu uute kirjanduslugude kirjutamiseks, mis arvestavad dünaamiliselt nii postkoloniaalsuse kui ka üleilmastuva kirjandusväljaga. Nende kolme teose lugemise põhjal on võimalik teha järeldusi, pakkuda soovitusi ning hoiatusi rahvuse ja romaani ning postkolonialismi teooria seostamise kohta eesti tänapäeva kirjandusuurimises.

\section{K i r j a n d u s}

Ahmed, Aijaz 2008. In Theory: Classes, Nations, Literatures. London: Verso.

Anderson, Benedict 2006 [1983]. Imagined Communities. London: Verso.

Bhabha, Homi K. 1990. Nation and Narration. London, New York: Routledge.

Bhabha, Homi K. 1994. The Location of Culture. London, New York: Routledge.

Culler, Jonathan 2003. Anderson and the Novel. - Grounds of Comparison: Around the Work of Benedict Anderson. Eds. J. Culler, P. Cheah. London, New York: Routledge, Ik 29-53.

Hitchcock, Peter 2010. The Long Space: Transnationalism and Postcolonial Form. Stanford: Stanford University Press.

Melas, Natalie 2007. All the Difference in the World: Postcoloniality and the Ends of Comparison. Stanford: Stanford University Press.

Parrinder, Patrick 2006. Nation \& Novel: The English Novel from its Origins to the Present Day. Oxford: Oxford University Press.

Spivak, Gayatri Chakravorty 2003. The Death of a Discipline. New York: Columbia University Press.

Tiina Kirss - Tallinna Ülikooli Eesti Humanitaarinstituudi kultuuriteooria professor. Ta on töötanud Toronto ülikooli eesti õppetooli keele ja kirjanduse õppejõuna ning korralise õppejõuna Merceri ülikoolis ja Wesleyan College's USAs. Peamisteks uurimisaladeks on 20. sajandi Euroopa kirjanduslugu, kirjandusteooria ja elulugu kui kirjutusvorm.

E-post: tiikirss@tlu.ee 